\title{
Patterns of pre-treatment drug abuse, drug treatment history and characteristics of addicts in methadone maintenance treatment in Iran
}

\author{
Hajar Shekarchizadeh ${ }^{1,2}$, Hamed Ekhtiari ${ }^{3,4}$, Mohammad R Khami ${ }^{1}$ and Jorma I Virtanen ${ }^{5,6^{*}}$
}

\begin{abstract}
Background: Opiates are the main drugs of abuse, and Methadone Maintenance Treatment (MMT) is the most widely administered drug addiction treatment program in Iran. Our study aimed to investigate patterns of pre-treatment drug abuse, addiction treatment history and characteristics of patients in MMT in Tehran.
\end{abstract}

Methods: We applied a stratified cluster random sampling technique and conducted a cross-sectional survey utilizing a standard patient characteristic and addiction history form with patients $(n=810)$ in MMT. The Chi-square test and $t$-test served for statistical analyses.

Results: A clear majority of the participants were men (96\%), more than $60 \%$ of whom were between 25 and 44 years of age, educated ( $89 \%$ had more than elementary education), and employed ( $>70 \%)$. The most commonly reported main drugs of abuse prior to MMT entry were opium (69\%) and crystalline heroin (24\%). The patients' lifetime drug experience included opium (92\%), crystalline heroin (28\%), cannabis (16\%), amphetamines (15\%), and other drugs (33\%). Crystalline heroin abusers were younger than opium users, had begun abusing drugs earlier, and reported a shorter history of opiate addiction.

Conclusion: Opium and crystalline heroin were the main drugs of abuse. A high rate of addiction using more dangerous opiate drugs such as crystalline heroin calls for more preventive efforts, especially among young men.

Keywords: Addiction, Opiates, Methadone Maintenance, Socioeconomic

\section{Introduction}

Drug abuse is among the most challenging and costly health problems that lead to a broad range of physical, mental, and psychiatric consequences, and poses a huge public health problem worldwide [1]. Opioids are the third most widely used group of drugs after cannabis and amphetamine-type stimulants. Among opioids, opiates are the most problematic and harmful substances consumed by 12 to 21 million people worldwide. The highest consumption rate of opiates is in countries in Southwest Asia [2].

Iran, located along the opium trade route, has the highest rate of opiate drug use worldwide [3]. Based on the most recent national survey of drug abuse in Iran, the

\footnotetext{
* Correspondence: jorma.virtanen@oulu.fi

${ }^{5}$ Department of Public Health, University of Helsinki, Helsinki, Finland ${ }^{6}$ Department of Community Dentistry, University of Oulu, P.O.Box 5281, Fl-90014, Oulu, Finland

Full list of author information is available at the end of the article
}

number of addicts in need of treatment services exceeds 1.2 million [4]. Opiates, mostly opium and crystalline heroin (heroin hydrochloride) [5], are the main drugs of abuse [6-8]. Recent years have seen a substantial shift from opium use towards using crystalline heroin: some new official estimates show that as many as $40 \%$ of opiate users consume opium, whereas the remaining users mostly consume different forms of heroin [2].

Generally, more than $80 \%$ of drug treatment admissions in Iran include opiate addicts seeking treatment [2]. Of various treatment methods, Methadone Maintenance Treatment (MMT) is considered the treatment of choice. According to Mokri and Schottenfeld [9], approximately 700 centers offered MMT to addicts in 2007. The treatment success among this group of addicts varies, but a multi-center study revealed a six-month retention rate of $23 \%$, often requiring repeated treatment episodes [10].

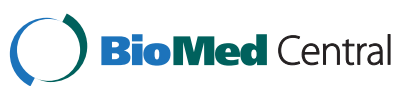


Effective preventive care, treatment planning, and policy-making requires knowledge of characteristics and background factors regarding drug addicts. Limited published data are available on patients seeking treatment in addiction treatment centers in Iran. Thus, this study aimed to investigate patterns of pre-treatment drug abuse, addiction treatment history, and background characteristics of patients in MMT attending addiction treatment centers in Tehran.

\section{Materials and Methods Subjects}

This study was a cross-sectional study of drug users attending methadone maintenance programs. The target population comprised all drug users attending methadone maintenance programs in addiction treatment centers in Tehran, Iran, in 2011. Based on the list of MMT clinics received from the Ministry of Health, more than $95 \%$ of the 160 addiction treatment centers in the city were private clinics. Thus, we focused on the clinics responsible for the major part of MMT and excluded the public centers from the study. We used a stratified cluster random sampling technique to cover the three main socioeconomic regions of the city: North, Center, and South.

Taking into account the proportion of clinics in each of the three strata, clinics were randomly selected as clusters in each study area. Based on the tariffs determined by the Ministry of Health in Iran, all private addiction treatment centers receive the same monthly fee from their patients. Thus, variation between the clinics in terms of the patient costs is minor. The region of the clinics makes use of the patients' living area as an indicator of their socioeconomic status. After contacting the heads of the clinics and introducing the study, we inquired about their willingness to participate. Among the first randomly selected eight clinics two did not agree to participate, thus two substitutes were randomly selected. Totally, two clinics in the North, and three clinics in both the Center and South areas participated in the survey. At these eight centers, patients receiving MMT were asked to participate. All these patients met DSM-IV criteria for opioid dependence [11]. Altogether 810 patients participated in the study from January to May 2011 (response rate $=72 \%$ ).

\section{Face-to-face interviews}

Three trained interviewers conducted structured interviews with the participants. Prior to the study, the interviewers received special training and agreed on the content of the interview, the organization of the clinics, and how to communicate with the patients. In the clinics, the interviewers used a standard patient characteristic form commonly used as a framework in addiction studies in Iran to conduct structured ten-minute in-person interviews. The interviewers requested information on patients' socioeconomic characteristics (age, gender, years of education, marital status, and job status), addiction history prior to treatment entry: all drugs used for at least one month in their lives, routes of abuse, the main drug of abuse (the most problematic drug, which was the main cause for treatment entry), age when the drug abuse began, the duration of addiction, and the total amount of money spent on drugs in the most recent month of abuse. In addition, the interviewers also inquired about the patients' MMT history: their previous methadone treatments, the duration of current treatment, and the patients' daily dose of received methadone.

The interviewers conducted the interviews in collaboration with the clinic nurse, who encouraged the patients to participate. Patients usually spent some time in the waiting room before receiving their medication or visiting their doctor, thus providing a good opportunity for the interview. The interviewer explained the study to the patients individually and inquired about their willingness to participate. After the interview, each patient received a toothbrush and toothpaste as a small gift. The data collection in each clinic continued to provide the monthly turnover of patients in the clinic based on the report provided by the clinic personnel.

\section{Ethical approval}

The data collection was carried out using an anonymous patient characteristic form which aimed to provide as much confidentiality as possible. The study was voluntary, and all respondents provided their written informed consent. The Tehran University of Medical Sciences Ethics Committee approved the study.

\section{Statistical analysis}

The data were transferred from the paper forms to a digital format. We performed statistical data analysis using the Statistical Package for the Social Sciences (SPSS for Windows, version 18), and analyzed any differences in frequencies using the Chi-square test; the $t$-test served to compare the means (level of significance $<0.05$ ).

\section{Results}

More than $95 \%$ of the participants receiving MMT were men, whereas women comprised $4 \%$ of the patients. The socioeconomic background of the participants appears in Table 1. The mean age of the patients was 40.5 years (SD 11.5; range 20-86), a majority (>60\%) of whom were between 25 and 44 years of age, married (70\%), and employed (> 70\%). Over $60 \%$ of the female participants were homemakers. As many as $89 \%$ of the patients had more than elementary school education (65\% high school and $24 \%$ university education), whereas the 
Table 1 Characteristics and main drug of abuse among patients receiving MMT $(n=810)$ in Tehran

\begin{tabular}{lllllll}
\hline Variable & Male & \multicolumn{3}{c}{ Female } & \multicolumn{2}{c}{ Total } \\
\cline { 2 - 8 } & $\mathbf{N}$ & $\%$ & $\mathbf{N}$ & $\%$ & $\mathbf{N}$ & $\%$ \\
\hline Age & & & & & & \\
\hline $18-24$ & 26 & 3 & 4 & 12 & 30 & 4 \\
\hline $25-34$ & 263 & 34 & 11 & 33 & 274 & 34 \\
\hline $35-44$ & 234 & 30 & 4 & 12 & 238 & 29 \\
\hline $45-54$ & 151 & 19 & 10 & 30 & 161 & 20 \\
\hline $55-64$ & 81 & 10 & 4 & 12 & 85 & 11 \\
\hline $65 \leq$ & 22 & 3 & - & - & 22 & 3 \\
\hline Total & 777 & & 33 & & 810 & \\
\hline
\end{tabular}

\section{Marital status}

\begin{tabular}{lllllll}
\hline Married & 541 & 70 & 23 & 70 & 564 & 70 \\
\hline Single & 164 & 21 & 4 & 12 & 168 & 21 \\
\hline Widow & 7 & 1 & 2 & 6 & 9 & 1 \\
\hline Divorced & 64 & 8 & 4 & 12 & 68 & 8 \\
\hline Total & 776 & & 33 & & 809 &
\end{tabular}

\section{Education status}

\begin{tabular}{lllllll}
\hline Illiterate & 12 & 2 & 5 & 16 & 17 & 2 \\
\hline Elementary school & 68 & 9 & 2 & 6 & 70 & 9 \\
\hline High school & 500 & 66 & 19 & 59 & 519 & 65 \\
\hline University & 183 & 24 & 6 & 19 & 189 & 24 \\
\hline Total & 763 & & 32 & & 795 &
\end{tabular}

\section{Job status (in the last 3 months)}

\begin{tabular}{lllllll}
\hline Full time job & 424 & 55 & 4 & 13 & 428 & 53 \\
\hline Unemployed & 115 & 15 & 4 & 13 & 119 & 15 \\
\hline Student & 10 & 1 & - & - & 10 & 1 \\
\hline Retired & 74 & 10 & 1 & 3 & 75 & 9 \\
\hline Part time job & 153 & 20 & 3 & 9 & 156 & 19 \\
\hline Homemaker & - & - & 20 & 63 & 20 & 3 \\
\hline Total & 776 & & 32 & & 808 &
\end{tabular}

\section{Main drug of abuse}

\begin{tabular}{lllllll}
\hline Opium & 534 & 69 & 19 & 59 & 553 & 69 \\
\hline Crystalline Heroin & 180 & 23 & 11 & 34 & 191 & 24 \\
\hline Other drugs & 60 & 8 & 2 & 6 & 62 & 8 \\
\hline Total & 774 & & 32 & & 806 & \\
\hline
\end{tabular}

others had an elementary school background (9\%) or were illiterate $(2 \%)$.

The most commonly reported main drug of abuse prior to treatment was opium (69\%), followed by crystalline heroin $(24 \%)$. Other drugs served as the main drug of abuse for about $8 \%$ of the participants: brown heroin base (3\%), Norjizak (vial heroin) (0.5\%) [12], amphetamines $(1.2 \%)$, methadone $(0.6 \%)$, cocaine $(0.1 \%)$, tranquilizers $(0.6 \%)$, and alcohol $(0.1 \%)$ among others. In terms of their lifetime history of drug abuse, more than $90 \%$ of the participants reported using opium, 28\% crystalline heroin, $16 \%$ cannabis, $15 \%$ amphetamines, and $33 \%$ other drugs for at least one month during their addiction period. Smoking and oral routes were the most prevalent routes of abuse reported by $79 \%$ and $48 \%$ of the participants, respectively. Snorting and injection were reported as routes of abuse by $5 \%$ of the participants. Table 2 presents the demographic characteristics of the participants according to the three major drug abuse groups. Crystalline heroin abuse was more prevalent in patients under 35 than was opium abuse $(p<0.001 ; \mathrm{df}=1)$, and crystalline heroin users were more educated than were opium users (mean 11.6 years vs. 10.6 years; $p<0.05$ ).

A summary of the addiction history of the patients in the three main drug abuse groups appears in Table 3. An overwhelming majority of addicts seeking treatment had used drugs for at least one year, whereas few (3\%) reported a history of addiction to drugs of less than one year. The mean duration of addiction among the patients was 10.8 years (SD 7.9). Generally, crystalline heroin abusers began abusing drugs earlier than did

Table 2 Characteristics of patients receiving MMT $(n=810)$ in Tehran according to their main drug of abuse

\begin{tabular}{lllll}
\hline Variable & \multicolumn{3}{l}{ Opium } & \multicolumn{3}{l}{ Crystalline Heroin } & Other Drugs & Total \\
\cline { 2 - 5 } & $\mathbf{( N ~ \% )}$ & $\mathbf{( N} \%)$ & $\mathbf{( N} \%)$ & $\mathbf{( N ~ \% )}$ \\
\hline Gender & & & $60(97)$ & $774(96)$ \\
\hline Male & $534(97)$ & $180(94)$ & $2(3)$ & $32(4)$ \\
\hline Female & $19(3)$ & $11(6)$ & 62 & 806 \\
\hline Total & 553 & 191 & & \\
\hline Age* & & & $1(2)$ & $30(4)$ \\
\hline $18-24$ & $9(2)$ & $20(11)$ & $32(52)$ & $272(34)$ \\
\hline $25-34$ & $140(25)$ & $100(52)$ & $20(32)$ & $238(30)$ \\
\hline $35-44$ & $161(29)$ & $57(30)$ & $5(8)$ & $159(20)$ \\
\hline $45-54$ & $140(25)$ & $14(7)$ & $4(7)$ & $85(11)$ \\
\hline $55-64$ & $81(15)$ & - & - & $22(3)$ \\
\hline $65 \leq$ & $22(4)$ & - & 62 & 806 \\
\hline Total & 553 & 191 &
\end{tabular}

\section{Education status*}

\begin{tabular}{lllll}
\hline Illiterate & $14(3)$ & $3(2)$ & - & $17(2)$ \\
\hline Elementary school & $60(11)$ & $6(3)$ & $4(7)$ & $70(9)$ \\
\hline High school & $347(64)$ & $127(68)$ & $42(69)$ & $516(65)$ \\
\hline University & $121(22)$ & $52(28)$ & $15(25)$ & $188(24)$ \\
\hline Total & 542 & 188 & 61 & 791
\end{tabular}

Job status (in the last 3 months)*

\begin{tabular}{lllll}
\hline Full time job & $305(55)$ & $93(49)$ & $28(45)$ & $426(53)$ \\
\hline Unemployed & $64(12)$ & $36(19)$ & $19(31)$ & $119(15)$ \\
\hline Student & $4(1)$ & $6(3)$ & - & $10(1)$ \\
\hline Retired & $70(13)$ & $2(1)$ & $3(5)$ & $75(9)$ \\
\hline Part time job & $97(18)$ & $47(25)$ & $11(18)$ & $155(19)$ \\
\hline Homemaker & $12(2)$ & $6(3)$ & $1(2)$ & $19(2)$ \\
\hline Total & 552 & 190 & 62 & 804 \\
\hline
\end{tabular}

*Variables with significant differences, $p<0.05$. 
Table 3 Addiction history of patients receiving MMT $(n=810)$ in Tehran according to their main drug of abuse

\begin{tabular}{lllll}
\hline Variable & $\begin{array}{l}\text { Opium } \\
(\mathrm{N} \%)\end{array}$ & $\begin{array}{l}\text { Crystalline heroin } \\
(\mathrm{N} \%)\end{array}$ & $\begin{array}{l}\text { Other drugs } \\
(\mathrm{N} \%)\end{array}$ & $\begin{array}{l}\text { Total } \\
(\mathrm{N} \%)\end{array}$ \\
\hline
\end{tabular}

\begin{tabular}{|c|c|c|c|c|}
\hline \multicolumn{5}{|c|}{ Age of starting drug abuse (years)* } \\
\hline$\leq 17$ & $55(10)$ & $43(23)$ & $11(18)$ & $109(14)$ \\
\hline $18-24$ & $210(38)$ & $102(53)$ & $31(51)$ & $343(43)$ \\
\hline $25-34$ & $187(34)$ & $43(23)$ & $14(23)$ & $244(31)$ \\
\hline $35 \leq$ & $97(18)$ & $3(2)$ & $5(8)$ & $105(13)$ \\
\hline Total (N) & 549 & 191 & 61 & 801 \\
\hline Mean (SD) & $26.2(8.6)$ & $21.2(5.3)$ & $23(7.8)$ & $24.8(8.2)$ \\
\hline \multicolumn{5}{|c|}{ Duration of addiction (years)* } \\
\hline$<1$ & $13(2)$ & $6(3)$ & $4(7)$ & $23(3)$ \\
\hline $1-5$ & $144(26)$ & $61(33)$ & $18(30)$ & $223(28)$ \\
\hline $6-10$ & $156(29)$ & $64(34)$ & $13(21)$ & $233(29)$ \\
\hline $11 \leq$ & $233(43)$ & $56(30)$ & $26(43)$ & $315(40)$ \\
\hline Total $(\mathrm{N})$ & 546 & 187 & 61 & 794 \\
\hline Mean (SD) & $11.6(8.4)$ & $8.7(6.2)$ & $9.9(7.8)$ & $10.8(7.9)$ \\
\hline \multicolumn{5}{|c|}{ Duration of current treatment (months)* } \\
\hline$<1$ & $67(12)$ & $21(11)$ & $5(8)$ & $93(12)$ \\
\hline $1-5.9$ & $144(26)$ & $61(32)$ & $12(20)$ & $217(27)$ \\
\hline $6-11.9$ & $126(23)$ & $47(25)$ & $4(7)$ & $177(22)$ \\
\hline $12-23.9$ & $112(20)$ & $32(17)$ & $10(16)$ & $154(19)$ \\
\hline $24 \leq$ & $102(19)$ & $29(15)$ & $30(49)$ & $161(20)$ \\
\hline Total $(\mathrm{N})$ & 551 & 190 & 61 & 802 \\
\hline Mean (SD) & $12.8(15.6)$ & $10.3(10.7)$ & $25.2(25.5)$ & $13.1(16)$ \\
\hline \multicolumn{5}{|c|}{ Number of previous MMT admissions* } \\
\hline 0 & $454(82)$ & $139(73)$ & $48(77)$ & $641(80)$ \\
\hline $1 \leq$ & $97(18)$ & $52(27)$ & $14(23)$ & $163(20)$ \\
\hline Total $(\mathrm{N})$ & 551 & 191 & 62 & 804 \\
\hline
\end{tabular}

Dosage of methadone (mg)*

\begin{tabular}{lllll}
\hline$\leq 30 \mathrm{mg}$ & $193(36)$ & $41(22)$ & $16(26)$ & $250(32)$ \\
\hline $35-65 \mathrm{mg}$ & $189(35)$ & $58(31)$ & $18(30)$ & $265(34)$ \\
\hline $70 \mathrm{mg} \leq$ & $158(29)$ & $90(48)$ & $27(44)$ & $275(35)$ \\
\hline Total (N) & 540 & 189 & 61 & 790 \\
\hline Mean (SD) & $57.9(51.6)$ & $70.5(46)$ & $80.7(75)$ & $62.6(52.9)$
\end{tabular}

Drug cost in the last month before treatment entry (\$)*

\begin{tabular}{lllll}
\hline$<50$ & $93(18)$ & $7(4)$ & $12(20)$ & $112(15)$ \\
\hline $50-99$ & $133(25)$ & $6(3)$ & $7(12)$ & $146(19)$ \\
\hline $100-199$ & $198(38)$ & $34(18)$ & $10(16)$ & $242(31)$ \\
\hline $200-499$ & $85(16)$ & $97(52)$ & $15(25)$ & $197(26)$ \\
\hline $500 \leq$ & $17(3)$ & $43(23)$ & $17(28)$ & $77(10)$ \\
\hline Total (N) & 526 & 187 & 61 & 774 \\
\hline
\end{tabular}

\begin{tabular}{lllll}
\hline Mean (SD) $133(155)$ & $381(372)$ & $303(278)$ & $206(259)$ \\
\hline
\end{tabular}

*Variables with significant differences, $p<0.05$.

opium users (mean 21.2 years vs. 26.2 years; $p<0.001$ ); the starting age for $76 \%$ of crystalline heroin abusers was under 25 years. The duration of addiction among crystalline heroin users was shorter than among opium users (mean 8.7 years vs. 11.6 years; $p<0.001$ ). Opium users reported smoking $(77 \%)$ and oral route $(58 \%)$ as the most common routes of abuse prior treatment. Among crystalline heroin abusers smoking (94\%) was the most prevalent route of use (Table 4).

For the vast majority $(80 \%)$ of patients, the treatment program they were already in was their first MMT episode (Table 3). The mean duration of current treatment was 13.1 months (SD 16) and it had lasted at least six months for most of them (61\%). The dose of methadone participants received ranged from $1.20 \mathrm{mg}$ to $500 \mathrm{mg}$ (mean 62.6; SD 52.9; median 55.0). The duration of current treatment was shorter (mean 10.3 months vs. 12.8 months; $p<0.05$ ) and the dosage of methadone was higher among crystalline heroin users than among opium users (mean $70.5 \mathrm{mg}$ vs. $57.9 \mathrm{mg} ; p<0.05$ ).

About two-thirds of the patients (67\%) reported spending at least USD 100 per month (mean USD 200) on their drugs during the last month prior to treatment (Table 3). Crystalline heroin users reported the highest monthly drug expenses: $75 \%$ of them spent at least USD 200 per month on their drugs whereas fewer than $20 \%$ of opium users spent an equivalent amount on theirs.

\section{Discussion}

Our study shows that in Tehran, patients receiving MMT predominantly used opium and crystalline heroin, whereas other drugs were the main drugs for only a minority of MMT patients. Generally, the clear majority of participants receiving MMT were young, educated, married, and employed men.

According to the world drug report, in 2009, between 149 and 272 million people between the ages of 15 and 64 consumed illegal drugs, of whom about $10 \%$ to $20 \%$ were considered dependent and regular drug users [2]. Patterns of drug dependency vary across countries: Iran, with more than one million regular drug users, has the world's highest rate of dependence on opiate drugs [3,4].

Tehran, as the capital of Iran and with a population exceeding 12 million, comprises a considerable section of the population. This study was conducted on MMT patients of private outpatient treatment centers in Tehran. Because public centers are so few, our sample provides a good overview of patients participating in MMT programs. MMT is the main treatment for opiate users available at official outpatient medical addiction treatment centers; consequently, this sample sheds light on the majority of opiate addiction treatment seekers who were referred to this official network.

Opium seems still to be the drug of choice among Iranian addicts given that most studies in Iran acknowledged the higher frequency of addiction to opium than to other drugs $[6,8]$. Our results are similar to the findings of a previous study of a group of drug addicts 
Table 4 Routes of using drugs prior to treatment among MMT patients $(\mathbf{n}=810)$ in Tehran according to their main drug of abuse

\begin{tabular}{|c|c|c|c|c|}
\hline Variable & $\begin{array}{l}\text { Opium } \\
\text { (N \%) }\end{array}$ & $\begin{array}{l}\text { Crystalline heroin } \\
\text { (N \%) }\end{array}$ & $\begin{array}{l}\text { Other drugs } \\
\text { (N \%) }\end{array}$ & $\begin{array}{l}\text { Total } \\
\text { (N \%) }\end{array}$ \\
\hline \multicolumn{5}{|c|}{ Smoking route } \\
\hline Yes & $425(77)$ & $180(94)$ & $29(48)$ & $634(79)$ \\
\hline No & $126(23)$ & $11(6)$ & $32(52)$ & $169(21)$ \\
\hline Total (N) & 551 & 191 & 61 & 803 \\
\hline \multicolumn{5}{|c|}{ Snorting (Sniffing) route } \\
\hline Yes & $4(1)$ & $14(7)$ & $10(16)$ & $28(4)$ \\
\hline No & 547 (99) & $177(93)$ & $51(84)$ & $775(96)$ \\
\hline Total (N) & 551 & 191 & 61 & 803 \\
\hline \multicolumn{5}{|c|}{ Oral route } \\
\hline Yes & $322(58)$ & $33(17)$ & $32(53)$ & $387(48)$ \\
\hline No & $229(42)$ & $158(83)$ & $29(47)$ & $416(52)$ \\
\hline Total (N) & 551 & 191 & 61 & 803 \\
\hline \multicolumn{5}{|c|}{ Injection route } \\
\hline Yes & $3(1)$ & $19(10)$ & $16(26)$ & $38(5)$ \\
\hline$\overline{N o}$ & $548(99)$ & $172(90)$ & $45(74)$ & $765(95)$ \\
\hline Total & 551 & 191 & 61 & 803 \\
\hline
\end{tabular}

seeking treatment in a general practice in Shiraz, which reported opium and heroin as the drugs most commonly abused [7]. The most recent Iranian rapid situation assessment of drug abuse in 2007 reported opium, crystalline heroin, and heroin to be the three most prevalent drugs previously abused by those attending treatment centers and in the general population [4]. Similar findings have also been reported in a multi-center study of seven outpatient centers in four Iranian cities [10]. The high prevalence of the history of opium use in our study compared to the estimates in the World Drug Report 2011 might be due to seeking treatment or less stigmatized self-report of using opium instead of heroin [2]. Only $1 \%$ of the patients reported amphetamines as their main drug of abuse, but as many as 15\% reported using this drug for at least one month in their lifetime prior to treatment. Since amphetamines are easily available in the Iranian drug market in comparison with other stimulants like cocaine [13], and that they may alleviate some of methadone side effects, they can cause a serious threat for the treatment process in the MMT clinics in Iran.

Crystalline heroin users were younger than opium users, and most of them had begun using drugs at younger ages. Moreover, the duration of addiction among crystalline heroin users tended to be shorter than among opium users. The amount of money most of the participants had spent on drugs was higher than the monthly MMT fee in these clinics (i.e. USD 80-90). This monthly treatment fee consists of a small proportion of the average monthly income of an urban family in Tehran [www.cbi.ir]. Crystalline heroin users had spent more money on their drugs during their last month of addiction than had opium addicts. Although a majority of the participants reported being under some kind of treatments earlier, most of them were receiving MMT for the first time. Overall, about $60 \%$ of the patients had been in MMT for more than six months. The mean daily dose of methadone among crystalline heroin users was higher than among opium users, but, it was in the recommended range of 60 to $120 \mathrm{mg}$ [14-16]. Although the mean daily dose of methadone was in the recommended range, as much as $30 \%$ of the patients received up to $30 \mathrm{mg}$ methadone. In Iran, methadone is usually prescribed in syrup or tablet forms. In our study the proportion of methadone in syrup and tablet forms among the MMT patients was about the same.

In line with previous findings, drug abuse is strongly related to male gender, particularly in the Eastern Mediterranean region [17-21]. Little is known about female addicts in the Middle East, and no comprehensive study on the prevalence of drug abuse among Iranian women exists. Consequently, it is unclear whether the low proportion of female participants in our study was due to a limited number of female addicts in general or their reluctance to seek professional help in treatment centers. Possible reluctance of women to give their consent to participate in the study was unlikely since the response rate among female participants $(74 \%)$ was close to the overall response rate $(72 \%)$.

In our study, most of the patients receiving MMT were fairly young. This is in line with a study by Day et al. [7] of drug abusers in a general practice in Shiraz, Iran. Another report of drug abuse among the general population in Kerman, however, found no significant association between drug abuse and age group [8]. Studies in other countries also show a higher prevalence of addiction among young people $[17,18,21,22]$.

In contrast with other studies of general populations that reveal lower rates of addiction among more educated people $[6,23]$, most of the MMT participants in our study had more than elementary school education. A study of drug abuse in Thailand reported somewhat similar findings among addicts in rural areas [21]. As a review article by Mokri [24] emphasized, most of the participants attending treatment centers in our study were also employed. Similar results emerged in another study of opioid-dependent patients seeking treatment in a major center in Shiraz [25]. In contrast, another study of opium use in a rural area of Iran found a significant association between opium use and unemployment [6]. On the other hand, in a population-based study of opium use in Fars province, opium use cut across all employment status groups [23]. The differences between 
the profile of MMT patients in our study and other studies in similar settings with general population of addicts reflect the diversity of the patients in terms of their socioeconomic status including education and employment. This indicates that in-treatment patients may be of higher socioeconomic level and may have more resources than the other addicts.

Bearing in mind that this study was a cross-sectional survey of patients attending outpatient addiction treatment centers, no causal inferences of underlying factors can be outlined. In addition, the findings from patients in MMT cannot be generalized to the whole population of drug users. One limitation of the study is that because of practical reasons only eight clinics were included in the study. Although the data are based on patients' selfreported addiction history, we tried to decrease the likelihood of underreporting via good collaboration with the clinic staff. However, it has to be kept in mind that tendency towards "social desirability" among clients in a good therapeutic alliance to caregivers can be a source of under-reporting. This limitation is true for all studies regarding drug abuse history.

Despite these limitations, our study has several strengths. The stratified random sampling method outlined well patients seeking treatment in addiction treatment centers from all three main socioeconomic areas of the city. In addition to the broad coverage, the large sample size along with the high response rate in this marginalized target group bolsters the reliability of the results in this capital city of more than 12 million. It is worth mentioning that our response rate of $72 \%$ may be somewhat low, as it is based on the number of study participants among the total monthly turnover in the clinics, rather than on the number of patients asked to participate. Furthermore, by utilizing a structured interview instead of a self-administered questionnaire, we reduced the possibility of misunderstandings in this compromised group.

Our study provides valuable information about the characteristics of patients attending addiction treatment centers in Iran. Although Tehran represents a considerable proportion of the Iranian population, a national survey of all drug abusers would be necessary to obtain a more thorough understanding of the predisposing factors associated with illegal drug abuse.

\section{Conclusion}

The present study has demonstrated that among Iranian former drug addicts attending addiction treatment centers, opium and crystalline heroin are the drugs of choice. The growing number of addicts utilizing more dangerous drugs such as crystalline heroin calls for more educational and preventive strategies targeting younger age groups in particular.

\section{Abbreviations}

MMT: Methadone Maintenance Treatment.

\section{Competing interests}

The authors declare that they have no competing interests.

\section{Acknowledgements}

This study has been supported by Tehran University of Medical Sciences and Health Services grant number 12900. Our special thanks go to Dr. Simin Mohebbi for her supportive consultations in the research project.

\section{Author details}

${ }^{1}$ Community Oral Health Department, School of Dentistry, Tehran University of Medical Sciences, Tehran, Iran. ${ }^{2}$ Department of Oral Public Health, University of Helsinki, Helsinki, Finland. ${ }^{3}$ Translational Neuroscience Program, Institute for Cognitive Science Studies, Tehran, Iran. ${ }^{4}$ Neurocognitive Laboratory, Iranian National Center for Addiction Studies, Tehran University of Medical Sciences, Tehran, Iran. ${ }^{5}$ Department of Public Health, University of Helsinki, Helsinki, Finland. ${ }^{6}$ Department of Community Dentistry, University of Oulu, P.O.Box 5281, Fl-90014, Oulu, Finland.

\section{Authors' contribution}

All authors were involved in the study concept and design. HS carried out data collection. HS and JV performed statistical analyses and interpretation of the data. All authors participated in writing of manuscript. All authors read and approved the final manuscript.

Received: 9 December 2011 Accepted: 7 June 2012

Published: 7 June 2012

\section{References}

1. Chen CY, Lin KM: Health consequences of illegal drug use. Curr Opin Psychiatry 2009, 22:287-292.

2. UNODC: World Drug Report 2011 (United Nations Publication, Sales No. E.11.XI.10); 2011.

3. UNODC: World Drug Report 2008 (United Nations Publication, Sales No. E.08.XI.1); 2008.

4. Iranian Drug Control Headquarter (IDCH): National Rapid Situation Analysis of Drug Abuse Status in Iran. Iran: Presidency; 2007.

5. Zerell U, Ahrens B, Gerz P: Documentation of a heroin manufacturing process in Afghanistan. Bull Narc 2005, 57:11-31.

6. Meysamie A, Sedaghat M, Mahmoodi M, Ghodsi SM, Eftekhar B: Opium use in a rural area of the Islamic Republic of Iran. East Mediterr Health J 2009, 15:425-431.

7. Day C, Nassirimanesh B, Shakeshaft A, Dolan K: Patterns of drug use among a sample of drug users and injecting drug users attending a General Practice in Iran. Harm Reduct J 2006, 3:2.

8. Ziaaddini $H$, Ziaaddini MR: The household survey of drug abuse in Kerman, Iran. J App/ Sci 2005, 5:380-382.

9. Mokri A, Schottenfeld R: Drug abuse and HIV transmission in Iran-Responding to the public health challenges. In Public Health Aspects of HIV/AIDS in Low and Middle Income Countries. Edited by Celentano D, Beyrer C. New York: Springer; 2008:583-599.

10. Shirinbayan P, Rafiey H, Vejdani Roshan A, Narenjiha H, Farhoudian A: Predictors of retention in methadone maintenance therapy: a prospective multi-center study. Sci Res Essay 2010, 5:3231-3236.

11. American Psychiatric Association (APA): Diagnostic and Statistical Manual of Mental Disorders. Fourth Edition. Text Revision. Washington, DC: American Psychiatric Association; 2000.

12. Siavash M, Janghorbani M, Gheshlaghi F, Adeli SH, Saljoughi M, Moradi F Majidinezhad M: A case series of abuse of a new opioid combination, Norjizak. J Addict Dis 2009, 28:180-185.

13. UNODC: Amphetamines and Ecstasy, 2011 Global ATS Assessment (United Nations Publication, Sales No. E.11.XI.13); 2011.

14. Bao YP, Liu ZM, Epstein DH, Du C, Shi J, Lu L: A meta-analysis of retention in methadone maintenance by dose and dosing strategy. Am J Drug Alcohol Abuse 2009, 35:28-33.

15. WHO: Guidelines for the psychosocially assisted pharmacological treatment of opioid dependence. Geneva: WHO Press; 2009.

16. Department of Health (England) and the devolved administrations: Drug Misuse and Dependence: UK Guidelines on Clinical Management. London: 
Department of Health (England), the Scottish Government, Welsh Assembly Government and Northern Ireland Executive; 2007.

17. Ali H, Bushra R, Aslam N: Profile of drug users in Karachi city, Pakistan. East Mediterr Health J 2011, 17:41-45.

18. Deng Q, Tang Q, Schottenfeld RS, Hao W, Chawarski MC: Drug use in rural China: a preliminary investigation in Hunan Province. Addiction 2012, 107:610-613.

19. Huang K, Zhang L, Liu J: Drug problems in contemporary China: a profile of Chinese drug users in a metropolitan area. Int J Drug Policy 2011, 22:128-132.

20. Ithan IO, Yildirim F, Demirbas H, Dogan YB: Prevalence and sociodemographic correlates of substance use in a university-student sample in Turkey. Int I Public Health 2009, 54:40-44.

21. Barrett ME: Correlates of illicit drug use in Karen villages in Northern Thailand. Subst Use Misuse 2003, 38:1615-1649.

22. Lu L, Fang Y, Wang X: Drug abuse in China: past, present and future. Cell Mol Neurobiol 2008, 28:479-490.

23. Ahmadi J, Pridmore S, Alimi A, Cheraghi A, Arad A, Parsaeyan H, Mohagheghzadeh MS, Kianpour M: Epidemiology of opium use in the general population. Am J Drug Alcohol Abuse 2007, 33:483-491.

24. Mokri A: Brief overview of the status of drug abuse in Iran. Arch Iranian Med 2002, 5:184-190.

25. Ahmadi J, Motamed F: Treatment success rate among Iranian opioid dependents. Subst Use Misuse 2003, 38:151-163.

doi:10.1186/1477-7517-9-18

Cite this article as: Shekarchizadeh et al:: Patterns of pre-treatment drug abuse, drug treatment history and characteristics of addicts in methadone maintenance treatment in Iran. Harm Reduction Journal 2012 9:18.

\section{Submit your next manuscript to BioMed Central and take full advantage of:}

- Convenient online submission

- Thorough peer review

- No space constraints or color figure charges

- Immediate publication on acceptance

- Inclusion in PubMed, CAS, Scopus and Google Scholar

- Research which is freely available for redistribution 